\title{
The Frequency of Allergic Bronchopulmonary Aspergillosis in Patients with Asthma
}

\author{
Mahdi Saleh Mahdi*, Samet Alyas Qasim**, Professor Ali Abdulmuttalib Mohammed*** \\ *Department of Allergy, Aljumhori Teaching Hospital, Mosul, ** Department. of Medicine, Alkofa Medical College, Alkofa, \\ ${ }^{\star \star \star}$ Department of Surgery, College of Medicine, University of Mosul, Mosul. \\ Correspondence: Professor Ali Abdulmuttalib. aamuttalib@yahoo.com
}

(Ann Coll Med Mosul 2019; 41 (2):117-124).

Received:25 $5^{\text {th }}$ Feb. 2019; Accepted:1 ${ }^{\text {st }}$ Dec. 2019.

\section{ABSTRACT}

Background: Allergic bronchopulmonary aspergillosis ABPA is an unusual but not rare illness that affects young atopic adults with allergic asthma. There are clinical and laboratory tests for the diagnosis of ABPA, these tests include history of asthma, peripheral blood eosinophilia, immediate cutaneous reactivity to Aspergillus fumigatus, serum precipitating antibodies to $A$. fumigatus or elevated total serum $\operatorname{lgE}$ and radiological infiltration.

Objectives: This is a case control study designed to evaluate the frequency of allergic bronchopulmonary aspergillosis ABPA in patients with asthma.

Methods: This is a case control study carried on 150 asthmatic patients consulting the allergic disease center of Aljumhori Teaching Hospital in Mosul for the period from November 2003 to July 2004 to identify patients with allergic bronchopulmonary aspergillosis ABPA. Their ages ranged from $6-65$ years, $52 \%$ of them were females and $48 \%$ were males. The results were compared with a 60 apparently healthy individuals selected randomly as a control group.

To prove that patients' symptoms were allergic bronchopulmonary aspergillosis ABPA, the following tests were performed for all patients, peripheral eosinophilia which was found in $40.6 \%$ of asthmatic patients, skin test for Aspergillus which was positive in $51.3 \%$, ELISA test for total $\lg$ E which was positive in $28 \%$ and chest- $X$ ray abnormalities were found in $17.3 \%$ of patients mainly as pulmonary infiltration.

Results: The major criteria for allergic bronchopulmonary aspergillosis ABPA were found in $19(12.6 \%)$ patients out of 150. Moreover, it was significantly higher in most age groups mainly in those patients between 6-15 years and 16-25 years of age. Peripheral eosinophilia, Skin test, ELISA and CXR did not appear to be related to the sex of patients or duration of asthma, but they were significantly higher than the control group $(P<0.05)$ in those with atopic asthma associated with other allergic diseases as eczema, urticaria, rhinitis and conjunctivitis.

Conclusion: The current study revealed that $12.6 \%$ of asthmatic patients fulfill the criteria of allergic bronchopulmonary aspergillosis ABPA and there was a significant relationship between asthma and Aspergillus fumigatus as a risk factor.

Keywords: Asthma, allergic bronchopulmonary aspergillosis ABPA, peripheral blood eosinophilia, skin test, $\lg \mathrm{E}$.

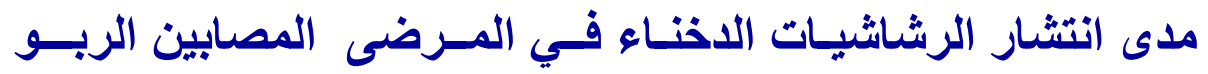

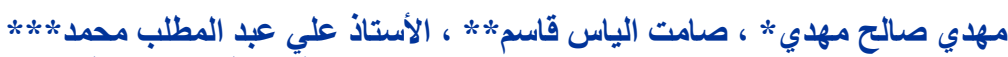

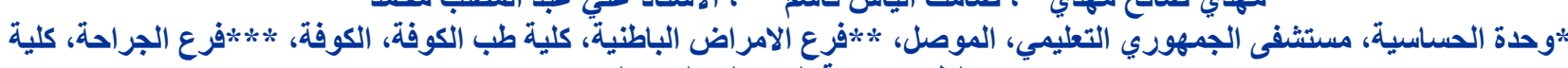

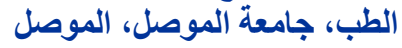


الخلاصة

مقدمة: تعتبر الرشاشيات الدخناء إحدى العو امل الخطرة التي تصيب مرضى الربو و التي تؤدي بدور ها إلى عدة أمر اض للشخص

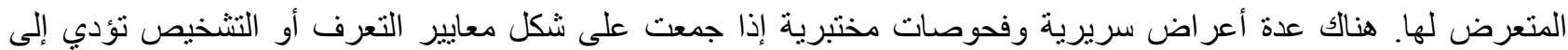

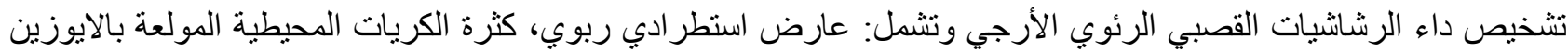

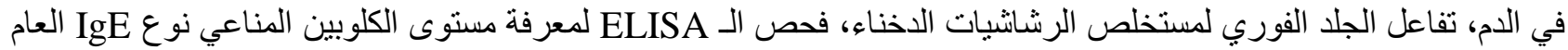

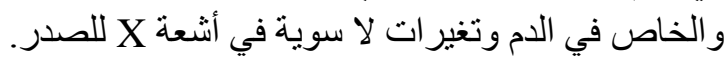

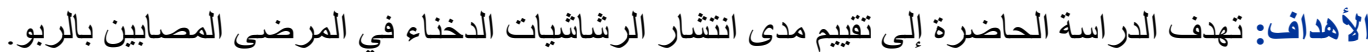

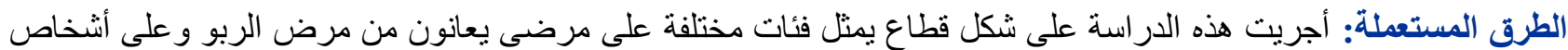

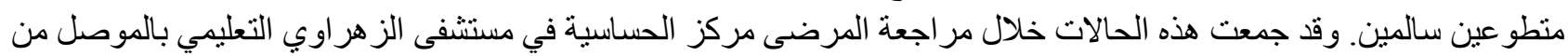

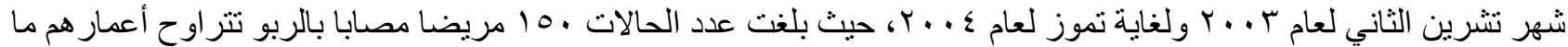

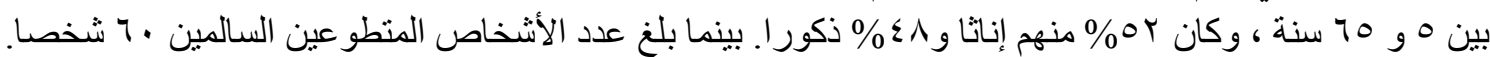
لغرض تطبيق معيار التعرف لغرض تشان اهنيص ABPA أجريت الفحوصات التالية: 1. فحص الكريات المحيطية المولعة بالايوزين في الدم. وكانت النتيجة موجبة (أي أن هناك ارتفاع في نسبة هذه الكريات) في

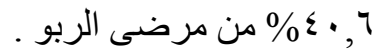

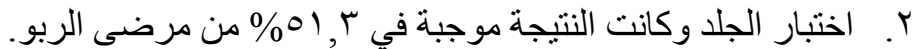

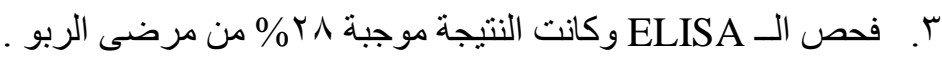

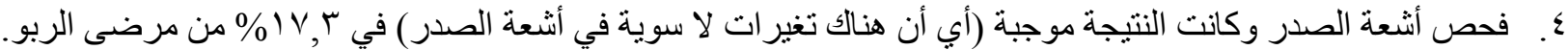

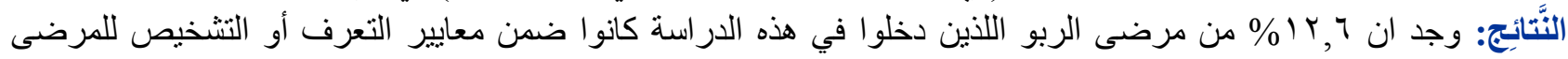

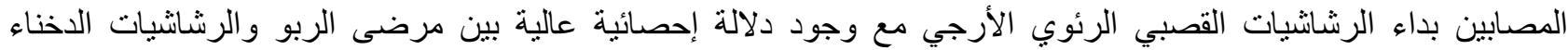
Aspergillus fumigatus

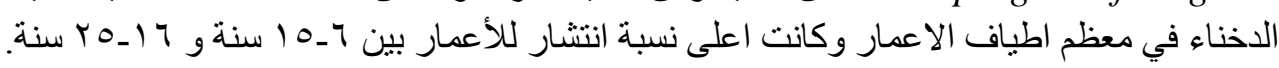

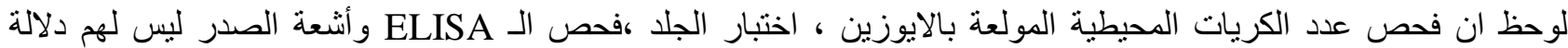

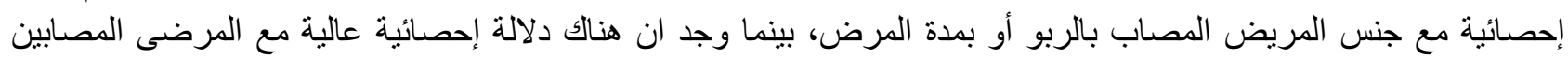

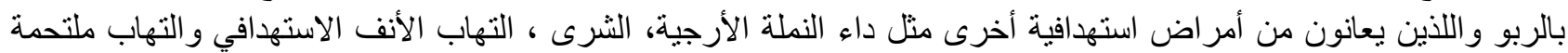
العين الأرجي.

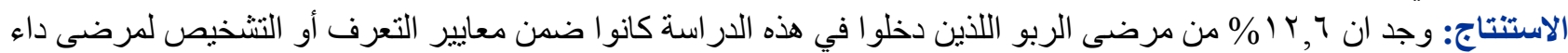

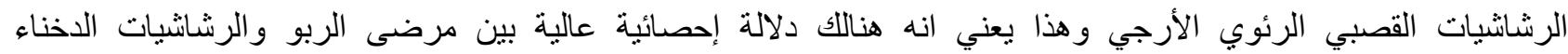
Aspergillus fumigatus الكلمات المفتاحية : الربو, داء الرشاشيات القصبي الرئوي الأرجي, الرشاشيات الدخناء, الكريات المحيطية المولعة بالايوزين, اختبار الجلد, IgE .

\section{INTRODUCTION}

A sthma is defined as a chronic inflammatory disorder of the airways, in which many cells and cellular elements play a role. Chronic inflammation is associated with airway hyperresponsiveness that leads to recurrent episodes of wheezing, breathlessness, chest tightness and coughing particularly at night and in early morning ${ }^{1}$

Aspergillosis is defined as infection with one or more species of the genus Aspergillus. Spore like structures called conidia are aerosolized from mold form of organism growing in the environment. When conidia reach tissue, they germinate to form invasive filaments called hyphae ${ }^{2}$. Allergic bronchopulmonary aspergillosis ABPA occurs as a result of hypersensitivity reactions after the colonization of the respiratory tract with Aspergillus most commonly $A$. fumigatus. The syndrome occurs largely in atopic patients with underlying asthma. It was first described in $1952^{3}$. There may be areas of lung collapse and bronchiectasis due to 
plugging of a bronchus by casts. A typical cast contains inspissated mucus, often with fungal hyphae; the production of fungal casts is diagnostic. In their absence, however, skin testing with Aspergillus antigen shows immediate type I and type III reaction in $90 \%$ of cases and precipitating and RAST antibodies to Aspergillus are detectable in the serum ${ }^{4}$.

Allergic bronchopulmonary aspergillosis ABPA is an unusual but not rare illness that affects young atopic adults with allergic asthma. Aspergillus causes inflammation in the lungs and allergic symptoms such as coughing and wheezing, but does not cause an infection. It is caused by concomitant $\lg \mathrm{E}$ and $\lg \mathrm{G}$ antibodies response to the ubiquitous fungus Aspergillus fumigatus. The disease may occur in infants and children. It can cause bronchiectasis and other destructive lung changes but tissue damage can be prevented if the conditions are diagnosed and treated properly ${ }^{3,5,6}$.

It is estimated that allergic bronchopulmonary aspergillosis ABPA occurs in1-10\% of patients with asthma, with rare exceptions, it is a disease of persons with atopic asthma, but it is also occurs in $10 \%$ of children with cystic fibrosis ${ }^{7}$.

It is also becoming clear that many asthmatics with an even severe form of fungal inflammatory lung disease, usually due to Aspergillus fumigatus and known ABPA, are often not properly diagnosed and have significant unmet diagnostic and therapeutic needs. The pathophysiology of allergic bronchopulmonary aspergillosis results from florid T-helper cell(TH)2 innate and adaptive immune responses in susceptible hosts who are unable to efficiently clear the respiratory epithelium of inhaled fungal spores ${ }^{8}$. Moreover, the diagnosis of allergic bronchopulmonary aspergillosis ABPA depends on $^{1,2,3}$.

\section{Major Criteria}

1. History of asthma (regardless of severity).

2. Central (proximal) broncheictasis.

3. Immediate skin reactivity for $A$. fumigatus.

4. Elevated total serum $\lg E(>1000 \mu \mathrm{g} / \mathrm{L})$.

5. Elevated $\lg \mathrm{E}$ or $\lg \mathrm{G}$ for $A$. fumigatus.

\section{Minor Criteria}

1. Peripheral blood oesinophilia.

2. Precipitating antibodies to A. fumigatus.

3. Pulmonary opacities or infiltrates.
The aim of this study is to evaluate the frequency of allergic bronchopulmonary aspergillosis ABPA in patients with asthma.

\section{PATIENTS AND METHODS}

This is a case control study designed to evaluate the frequency of Aspergillus fumigatus among patients with asthma. After taking the consent of patients, one hundred fifty asthmatic patients consulting allergic disease center at Aljumhori Teaching Hospital in Mosul for the period from November 2003 to July 2004 were included in the study. Seventy-two patients (48\%) were males and seventy-eight $(52 \%)$ patients were females.

For the diagnosis of asthma, we depend on the typical history of asthma, clinical examination (presence of rhonchi and wheezes) and estimation of PEFR and PFT(FEV,$F V C$ and $\left.\mathrm{FEV}_{1} / \mathrm{VC}\right)$. Pulmonary function tests were performed at the same hospital. Moreover, All tests were free of charge.

\section{Peripheral Blood Eosinophilia}

Complete blood picture and ESR including total WBC and differential count were done for all patients. The differential white cells count was done in a well-spread film and examined under the oil immersion lens.

\section{Skin Test}

Skin test was done by intradermal injection of $A$. fumigatus antigens and the result was indicated by observation of the patient for reaction in form of wheal and flare within 20-30 minutes. The following grading was dependent for the skin reaction: 0 No reaction.

$1+$ Wheal and erythema $<20 \mathrm{~mm}$ in diameter.

$2+$ Wheal and erythema $>20 \mathrm{~mm}$ in diameter.

3+ Large wheal and erythema.

4+ Wheal with pseudopods and erythema.

In this test a measured quantity of allergen is injected intradermally using a 27- gauge needle, after 20-30 minutes, the reaction is graded and recorded. The recommended volume ranges from $0.005-0.02$ $\mathrm{ml}$ but it is usually $0.01 \mathrm{ml}$. Negative and positive controls are used ${ }^{2}$. 


\section{Serological Tests}

Enzyme Linked Immunosorbant Assay-ELISA for total IgE.The machine used in this study is EL $x$ 800 Universal Microplate Reader / USA and the kit used was Direct ELISA kit for the quantitative determination of serum total $\lg E$ manufactured by Biomaghereb. 24 AV. Ibn Khaldon BT 543 ARIANA 2080/exp. In this study total IgE for A. fumigatus was detected for all asthmatic patients and control group3.

\section{Chest X-Ray}

Chest X-ray was done for every patient and the previous chest $X$-rays were examined when they were available. The chest $\mathrm{X}$-rays abnormalities findings can demonstrate non-homogeneous infiltration with smooth boarders, infiltrates with air fluid levels from dilated bronchi, areas of consolidation, lober or whole lung collapse, bronchiectasis. The upper or middle lobes commonly mainly affected in patient with ABPA. Any one of the radiological abnormalities mentioned above was considered as a criterion for diagnosis of ABPA4.

\section{Sputum Examination}

Sputum examinations including eosinophil count and mycological examination for $A$. fumigatus hyphae were done. Czapek -Dox agar is used for inoculation of $A$. fumigatus, the colony of $A$. fumigatus is downy to powdery in the texture. The surface color varies from blue-green to gray. On microscopical examination, hyphae of $A$. fumigatus shows frequent septate, colorless to gray hyphae, about 300 micrometer long, branching at 450 with single round - columnar head with very small 2-3 micrometer in diameter5.

\section{Control Group}

This group consisted of 60 apparently healthy individuals selected randomly. All the tests done for the asthmatic patients were also done for subjects in this group after taking their consent to participate in this study.

\section{Statistical Analysis}

Chi square test was used for statistical analysis between the groups.

\section{RESULTS}

One hundred fifty asthmatic patients and sixty apparently healthy control individuals were included in this study. Table 1 shows the age distribution for the asthmatic patients and control group. In control group there were 10 persons in each age group.

Table 1: Age distribution of patients involved in the study.

\begin{tabular}{ccccc}
\hline \multirow{2}{*}{$\begin{array}{c}\text { Age } \\
\text { Group } \\
\text { (Year) }\end{array}$} & \multicolumn{2}{c}{ Patients } & \multicolumn{2}{c}{ Control } \\
\cline { 2 - 5 } & NO. & $\%$ & NO. & $\%$ \\
\hline $6-15$ & 21 & 14.00 & 10 & 16.7 \\
\hline $16-25$ & 32 & 21.33 & 10 & 16.7 \\
\hline $26-35$ & 30 & 20.00 & 10 & 16.7 \\
\hline $36-45$ & 28 & 18.67 & 10 & 16.7 \\
\hline $46-55$ & 22 & 14.67 & 10 & 16.7 \\
\hline $56-65$ & 17 & 11.33 & 10 & 16.7 \\
\hline Total & 150 & 100 & 60 & 100 \\
\hline
\end{tabular}

Overall, major criteria for allergic ABPA was found in $19(12.6 \%)$ patients out of 150 . Moreover, it was significantly high in most age groups mainly in those patients between $6-15$ years and $16-25$ years of age Table 2 . 
Table 2 : Number and percentage of patients fulfill the criteria of ABPA.

\begin{tabular}{ccccc}
\hline \multirow{2}{*}{$\begin{array}{c}\text { Age group } \\
\text { (year) }\end{array}$} & $\begin{array}{c}\text { Number of } \\
\text { patients }\end{array}$ & \multicolumn{2}{c}{$\begin{array}{c}\text { Patients with } \\
\text { ABPA }\end{array}$} & $\begin{array}{c}\text { P- } \\
\text { value }\end{array}$ \\
\cline { 3 - 4 } & & No. & $\%$ & \\
\hline $6-15$ & 21 & 7 & 33.3 & $<0.01$ \\
\hline $16-25$ & 32 & 10 & 31.2 & $<0.05$ \\
\hline $26-35$ & 30 & 1 & 3.3 & $<0.05$ \\
\hline $36-45$ & 28 & 0 & 0.0 & - \\
\hline $46-55$ & 22 & 1 & 4.5 & $<0.05$ \\
\hline $56-65$ & 17 & 0 & 0.0 & - \\
\hline Total & 150 & 19 & 12.3 & \\
\hline
\end{tabular}

parameters listed before were significantly higher in asthmatic patients than the control group.

Table 3 : Comparison between asthmatic patients and the control group regarding eosinophilia, skin test, ELISA and CXR.

\begin{tabular}{|c|c|c|c|c|c|}
\hline \multirow[t]{2}{*}{ Test } & \multicolumn{2}{|c|}{$\begin{array}{l}\text { Patients } \\
(n=150)\end{array}$} & \multicolumn{2}{|c|}{$\begin{array}{l}\text { Control } \\
(n=60)\end{array}$} & \multirow[t]{2}{*}{ P-value } \\
\hline & No. & $\%$ & No. & $\%$ & \\
\hline $\begin{array}{l}\text { Peripheral } \\
\text { eosinophilia }\end{array}$ & 61 & 40.6 & 11 & 18.3 & $<0.05$ \\
\hline Skin Test & 77 & 51.3 & 1 & 1.6 & $<0.001$ \\
\hline ELISA & 42 & 28.0 & 2 & 3.3 & $<0.001$ \\
\hline CXR & 26 & 17.3 & 0 & 0.0 & $<0.01$ \\
\hline
\end{tabular}

Table 3 shows a comparison between asthmatic patients and the control group regarding peripheral eosinophilia, skin test, ELISA for Aspergillus fumigatus and CXR finding. Statistical analysis for all the

Table 4 shows the relationship between the sex of patients with peripheral eosinophilia, skin test, ELISA and CXR abnormalities, no statistically significant difference seen between both sexes.

Table 4 : The relationship between sex of patients and peripheral eosinophilia, skin test, ELISA and CXR abnormalities.

\begin{tabular}{|c|c|c|c|c|c|c|c|c|c|c|}
\hline \multirow[t]{2}{*}{$\begin{array}{l}\text { Sex of } \\
\text { patients }\end{array}$} & \multicolumn{2}{|c|}{$\begin{array}{c}\text { Number of } \\
\text { patients }\end{array}$} & \multicolumn{2}{|c|}{$\begin{array}{c}\text { Number of patients } \\
\text { with eosinophilia }\end{array}$} & \multicolumn{2}{|c|}{$\begin{array}{c}\text { Number of } \\
\text { patients with +ve } \\
\text { skin test }\end{array}$} & \multicolumn{2}{|c|}{$\begin{array}{c}\text { Number of } \\
\text { patients with +ve } \\
\text { ELISA }\end{array}$} & \multicolumn{2}{|c|}{$\begin{array}{c}\text { Number of patients } \\
\text { with CXR } \\
\text { abnormalities }\end{array}$} \\
\hline & No. & $\%$ & No. & $\%$ & No. & $\%$ & No. & $\%$ & No. & $\%$ \\
\hline \multirow{2}{*}{ Male } & 72 & 48 & 29 & 40.3 & 40 & 55.5 & 20 & 27.7 & 12 & 16.6 \\
\hline & \multicolumn{2}{|c|}{$P>0.05$} & \multicolumn{2}{|c|}{$P>0.05$} & \multicolumn{2}{|c|}{$P>0.05$} & \multicolumn{2}{|c|}{$P>0.05$} & \multicolumn{2}{|c|}{$P>0.05$} \\
\hline \multirow{2}{*}{ Female } & 78 & 52 & 32 & 41 & 37 & 47.7 & 22 & 28.2 & 14 & 17.9 \\
\hline & \multicolumn{2}{|c|}{$P>0.05$} & \multicolumn{2}{|c|}{$P>0.05$} & \multicolumn{2}{|c|}{$P>0.05$} & \multicolumn{2}{|c|}{$P>0.05$} & \multicolumn{2}{|c|}{$P>0.05$} \\
\hline Total & 150 & & 61 & 40.6 & 77 & 51.3 & 42 & 25 & 26 & 17.3 \\
\hline
\end{tabular}


Table 5 shows the relationship between the duration of bronchial asthma and peripheral eosinophilia, skin test, ELISA and CXR findings. There was no significant difference in peripheral eosinophilia, skin test, ELISA and CXR findings in relation to the duration of bronchial asthma.

Table 5 : The relationship between duration of bronchial asthma and peripheral eosinophilia, skin test, ELISA and CXR abnormalities.

\begin{tabular}{|c|c|c|c|c|c|c|c|c|c|c|}
\hline \multirow{2}{*}{$\begin{array}{c}\text { Duration of } \\
\text { asthma } \\
\text { (year) }\end{array}$} & \multicolumn{2}{|c|}{$\begin{array}{c}\text { Number of } \\
\text { patients }\end{array}$} & \multicolumn{2}{|c|}{$\begin{array}{l}\text { Number of } \\
\text { patients with } \\
\text { eosinophilia }\end{array}$} & \multicolumn{2}{|c|}{$\begin{array}{c}\text { Number of } \\
\text { patients with +ve } \\
\text { skin test }\end{array}$} & \multicolumn{2}{|c|}{$\begin{array}{l}\text { Number of } \\
\text { patients with } \\
\text { +ve ELISA }\end{array}$} & \multicolumn{2}{|c|}{$\begin{array}{c}\text { Number of patients } \\
\text { with CXR } \\
\text { abnormalities }\end{array}$} \\
\hline & No. & $\%$ & No. & $\%$ & No. & $\%$ & No. & $\%$ & No. & $\%$ \\
\hline \multirow{2}{*}{$5 \geq$} & 53 & 35.3 & 26 & 49 & 28 & 52.8 & 19 & 35.8 & 12 & 22.6 \\
\hline & \multicolumn{2}{|c|}{$P>0.05$} & \multicolumn{2}{|c|}{$P>0.05$} & \multicolumn{2}{|c|}{$P>0.05$} & \multicolumn{2}{|c|}{$P>0.05$} & \multicolumn{2}{|c|}{$P>0.05$} \\
\hline \multirow{2}{*}{$6-10$} & 47 & 31.36 & 23 & 48.9 & 20 & 42.5 & 14 & 29.7 & 12 & 21.2 \\
\hline & \multicolumn{2}{|c|}{$P>0.05$} & \multicolumn{2}{|c|}{$P>0.05$} & \multicolumn{2}{|c|}{$P>0.05$} & \multicolumn{2}{|c|}{$P>0.05$} & \multicolumn{2}{|c|}{$P>0.05$} \\
\hline \multirow{2}{*}{$11-15$} & 23 & 15.3 & 4 & 17.3 & 14 & 60.8 & 4 & 17.3 & 3 & 13.0 \\
\hline & \multicolumn{2}{|c|}{$P>0.05$} & \multicolumn{2}{|c|}{$P>0.05$} & \multicolumn{2}{|c|}{$P>0.05$} & \multicolumn{2}{|c|}{$P>0.05$} & \multicolumn{2}{|c|}{$P>0.05$} \\
\hline \multirow{2}{*}{$16-20$} & 14 & 9.3 & 4 & 28.5 & 8 & 57.1 & 2 & 14.2 & 1 & 7.1 \\
\hline & \multicolumn{2}{|c|}{$P>0.05$} & \multicolumn{2}{|c|}{$P>0.05$} & \multicolumn{2}{|c|}{$P>0.05$} & \multicolumn{2}{|c|}{$P>0.05$} & \multicolumn{2}{|c|}{$P>0.05$} \\
\hline \multirow{2}{*}{$21-25$} & 11 & 7.3 & 3 & 27.2 & 7 & 63.6 & 3 & 27.2 & 0 & \\
\hline & \multicolumn{2}{|c|}{$P>0.05$} & \multicolumn{2}{|c|}{$P>0.05$} & \multicolumn{2}{|c|}{$P>0.05$} & \multicolumn{2}{|c|}{$P>0.05$} & \multicolumn{2}{|c|}{$P>0.05$} \\
\hline \multirow{2}{*}{$26 \leq$} & 2 & 1.3 & 1 & 50 & 0 & & 0 & & 0 & \\
\hline & & .05 & & & & & & & & \\
\hline
\end{tabular}

Table 6 shows the relationship between other allergic diseases in asthmatic patients with peripheral eosinophilia, skin test, ELISA and CXR findings. Ninety-four (62.6\%) asthmatic- patients gave history of other allergic diseases as conjunctivitis, eczema, drug allergy and insect allergy. Peripheral eosinophilia, positive skin test, positive ELISA test for Aspergillus fumigatus and CXR abnormalities were found to be significantly higher in asthmatic patients with other allergic diseases than those without other allergic diseases.

Table 6 : The relation of other allergic diseases in asthmatic patients with peripheral eosinophilia, skin test, ELISA and CXR abnormalities.

\begin{tabular}{|c|c|c|c|c|c|c|c|c|c|c|}
\hline \multirow{2}{*}{$\begin{array}{l}\text { Asthmatic } \\
\text { patients }\end{array}$} & \multicolumn{2}{|c|}{$\begin{array}{c}\text { Number of } \\
\text { patients }\end{array}$} & \multicolumn{2}{|c|}{$\begin{array}{l}\text { Number of patients } \\
\text { with eosinophilia }\end{array}$} & \multicolumn{2}{|c|}{$\begin{array}{c}\text { Number of patients } \\
\text { with + ve skin test }\end{array}$} & \multicolumn{2}{|c|}{$\begin{array}{c}\text { Number of } \\
\text { patients with +ve } \\
\text { ELISA }\end{array}$} & \multicolumn{2}{|c|}{$\begin{array}{c}\text { Number of patients } \\
\text { with CXR } \\
\text { abnormalities }\end{array}$} \\
\hline & No. & $\%$ & No. & $\%$ & No. & $\%$ & No. & $\%$ & No. & $\%$ \\
\hline $\begin{array}{c}\text { With other } \\
\text { allergic disease }\end{array}$ & 94 & 62.6 & 47 & 50 & 56 & 56 & 33 & 35 & 21 & 22.3 \\
\hline $\begin{array}{l}\text { Without other } \\
\text { allergic disease }\end{array}$ & 56 & 37.3 & 14 & 25 & 21 & 33.5 & 9 & 16.0 & 5 & 8.9 \\
\hline P-Value & \multicolumn{2}{|c|}{$<0.05$} & \multicolumn{2}{|c|}{$<0.05$} & \multicolumn{2}{|c|}{$<0.05$} & \multicolumn{2}{|c|}{$<0.05$} & \multicolumn{2}{|c|}{$<0.05$} \\
\hline
\end{tabular}


Microscopical examination of sputum for Aspergillus fumigatus was positive in 20(13.3\%) patients, $51(34 \%)$ patients gave history of brownishplug in the sputum, and $23(15.3 \%)$ patients gave history of late-onset skin reaction mediated by $\lg G$ and $\lg \mathrm{M}$.

\section{DISCUSSION}

Severe asthma with fungal sensitization and allergic bronchopulmonary aspergillosis encompasses two closely related subgroups of patients with severe allergic asthma. Pulmonary disease is due to pronounced host inflammatory responses to noninvasive subclinical endobronchial infection with filamentous fungi, usually Aspergillus fumigatus ${ }^{8}$.

The current study indicates that peripheral eosinophilia, skin test, ELISA for Aspergillus fumigatus antigens and radiological abnormalities are statistically significantly higher in asthmatic patients than the control group. Furthermore, allergic bronchopulmonary aspergillosis was more common in this study $12.3 \%$ than other studies $1-10 \%$ in Harris et. al. $2000^{\circ}$. study, and $7-10 \%$ in Becker et. al. $1996^{10}$ study, this appeared to be related to abuse and long duration use of steroid therapy. Other risk factors for invasive aspergillosis may include neutropaenia, solid organ or allogeneic stem cell transplantation, leukaemia and other haematological malignancies, cytotoxic chemotherapy, advanced HIV disease, severe chronic obstructive pulmonary disease, critically ill patients on intensive care units and chronic granulomatous disease ${ }^{1}$.

In a meta-analysis of 21 studies, the prevalence of sensitization to antigens in selected patients with asthma was $28 \%$. The prevalence of allergic bronchopulmonary aspergillosis in patients with asthma and those with Aspergillus hypersensitivity were $12.9 \%$ and $40 \%$ respectively. In addition to increasing risk of allergic bronchopulmonary aspergillosis, sensitization to Aspergillus antigens appears to increase the severity of asthma. The pathogenesis of allergic bronchopulmonary aspergillosis is not completely understood. There does not appear to be a correlation between Aspergillus load in the environment and the development of $A B P A^{11}$.

Allergic bronchopulmonary aspergillosis ABPA was found in $33 \%$ of those $6-15$ years old and in $31.2 \%$ of those 16-25 years old, these results were significantly higher than other age groups. On comparison, Shah
A and Panjabi , 2014 ${ }^{12}$ reported that ABPA usually seen in the 20-40 years age group and it has been also reported in children and even in infants. Similarly, Gupta, Chandra and Gautam 2012 ${ }^{13}$, stated that although ABPA is common in adults between 20-40 years of age many cases have been reported in younger age groups in India.

Peripheral eosinophilia was found in $40.6 \%$ of asthmatic patients, a similar result $37 \%$ was found by Milgrom and Fick in $1999^{14}$. Moreover, in this study $18.3 \%$ of the control group has eosinophilia, this is because the peripheral eosinophilia has many causes as helminthiasis.

Skin test for Aspergillus fumigatus was positive in $51.3 \%$ of asthmatic patients in our study whereas it was positive in $70 \%$ and $85 \%$ of asthmatic patients according to Tristram and Daniel, $2001^{5}$ study and Milgrom and Fick,199914 study respectively. The. Also the early childhood and infants' patients gave a false reading of skin test due to immaturity of immune system and the older age also gave a false result due to development of desensitization to this antigen and the strength of immune system are decreased. Other causes are immunosuppressive diseases.

ELISA test for Aspergillus fumigatus was positive in $28 \%$ of asthmatic patients in this study, while it was positive in $45 \%$ and $50 \%$ in Milgrom and Fick, $1999^{14}$ study and Words and Lee, $1999^{15}$ study, respectively. Moreover, when a patient with asthma appears to have ABPA, but serologic tests are not consistent, one issue is whether that laboratory results are spurious because of poorly reactive fungi used in precipitating $\mathrm{Ab}$. test and enzyme assay to detect anti- Aspergillus fumigatus $\lg E$ or $\lg G$ antibodies. Another possibility is the presence of another aetiological species of Aspergillus, such as Aspergillus terrerus, Aspergillus glaucus or Aspergillus niger.

Radiological abnormalities were found in $17.3 \%$ of asthmatic patients, while it was positive in $7-10 \%$ of patients as in Mehard et. al., $2001^{16}$ study of patients in other studies. This may depend on the time of radiological examination since pulmonary infiltrates, which are the most common radiological abnormalities of ABPA, are transient and CXR should be done at appropriate time to detect these abnormalities. Kousha et. al. $2011^{11}$ stated that chest radiorgraph may be normal in early stages of the disease. During acute exacerbations, fleeting pulmonary infiltrates are a characteristic feature of 
the disease that tend to appear in the upper lobe and are central in location. The "ring sign" and "tram lines" are radiological signs that represent the thickened and inflamed bronchi and may be seen in chest radiography. At later stages, central bronchiectasis and pulmonary fibrosis may develop.

It was found in this study that the percentage of CXR abnormalities is more than that of Mehard et. al. $2001^{16}$, this is probably because the CXR in most of patients of ABPA are to bear little or no relationship to severity or chronicity of the disease.

Peripheral eosinophilia, skin test for Aspergillus fumigatus,ELISA for Aspergillus fumigatus and CXR abnormalities were not related to duration of asthma or sex of the patients, but they were significantly higher in patients with bronchial asthma with other allergic diseases than those without other allergic diseases. This is in concordance to the results of Paul, $1999^{17}$. This is probably because in asthmatic patients with history of other allergic diseases had inherited tendency or familial tendency for hyper production of $\lg \mathrm{E}$ antibodies to common environmental allergens and the Aspergillus fumigatus is one of them. So, these patients regarded as atopic patients.

\section{CONCLUSION}

Allergic bronchopulmonary aspergillosis was found in $12.6 \%$ fasthmatic patients and it was more common in younger than older patients. There was no significant relation between duration of asthma and sex of patients with allergic bronchopulmonary aspergillosis.

\section{REFERENCES}

1. Reid PT and Innes JA. Respiratory Medicine: In: Davidson's Principles and practice of medicine. 23thed.Elsevier Publisher; 2018: 596-598.

2.Walsh TJ and Stevens DA. Aspergillosis: In: Goldman's Cecil Medicine. 24ed; 1, 2012: 19901994.

3.Austen KF, Frank MM, Atkinson JP and Cantor $\mathrm{H}$. Allergic bronchopulmonary aspergillosis: In: Samter's Immunologic Diseases. 6th ed. Lippincott Williams and Wilkins Publishers; 2001: 686.

4. Chapel H, Haeney M, Misbah S and Snowden N. Allergic bronchopulmonary aspergillosis (ABPA). In; Essentials of Clinical Immunology. Sixth ed. Wiley Blackwell Publisher. 2014: 253-254.
5.Tristram G.P., Daniel PS. Allergic Diseases, Allergic bronchopulmonary aspergillosis: Medical immuonology.I0th ed; 2001:242-671.

6. Agarwal R, Chakrabarti A, Shah A, Gupta D Meis JF, Guleria R, et al. Allergic bronchopulmonary aspergillosis: review of literature and proposal of new diagnostic and classification criteria. Clin Exp Allergy. 2013; 43(8): 850-73

7.Becker JW, Bruker W, McDonald G. J.W., Bruker W. McDonald G. Prevalence of allergic bronchopulmonary aspergillosis in adult patient, chest. 1996; 109:1536-1540.

8. Moss RB. Treatment options in severe fungal asthma and allergic bronchopulmonary aspergillosis. European Respiratory Journal 2014 43: 1487-1500.

9. Harris KE, Patterson R, Greenberger PA Allergic bronchopulmonary aspergillosis. Chest. 2000; 118:7-8.

10. Becker JW, Bruker W, McDonald G.. J.W., Bruker W., McDonald G.. Prevalence of allergic bronchopulmonary aspergillosis in adult patients. Chest. 1996; 109:1536-1540.

11. Kousha M, Tadi R and Soubani AO. Pulmonary aspergillosis: a clinical review. Eur Respir Rev 2011; 20:121, 156-174.

12. Ashok Shah and Chandramani Pajabi. Allergic aspergillosis of the respiratory tract. European Respiratory Review 2014; 23: 8-29.

13. Rajesh Kumar Gupta, Amol Chandra, Praveen Bahadur Gautam. Allergic Bronchopulmonary Aspergillosis - A Clinical Review. JAPI April 2012 VOL. 60.

14. Milgrom $\mathrm{H}$, Fick RB, et al.Treatment of allergic asthma with Monocolonal anti-lgE. Engl J Med. 1999; 23:1966-73.

15. Words $S$ and LeeMJ. Allergic bronchpulmonary aspergillosis in asthmatic patients. BMJ. 1999; 173: 937-42.

16. Mehard B, Paciocco G, Martinez FD, et al.Spectrum of aspergillus infection. Chest. 2001; 119: 169-175.

17. Paul AG. Allergic bronchopulmonary aspergillosis. Best practice of Medicine.1999;30: 65-78. 